\title{
The influence of whole body cryotherapy on plasma concentration of melatonin and serotonin in patients with osteoarthrosis of the lumbar spine
}

Authors' Contribution: A Study Design

B Data Collection

C Statistical Analysis

D Data Interpretation

E Manuscript Preparation

F Literature Search

G Funds Collection

\author{
Marta Barłowska-Trybulec ABCDEFG, Joanna Szklarczyk ${ }^{B D}$, Jolanta Jaworek ABC \\ Department of Medical Physiology, Institute of Physiotherapy, Faculty of Health \\ Sciences, Jagiellonian University Medical College, Cracow, Poland
}

\section{abstract}

Background:

Material and methods:

Results: Following therapy, the functional efficiency (RMDQ) improved by $33 \%$ in both study groups $(p<0.0001)$. After the therapy, both in the group of patients undergoing WBCT combined with exercises (group $A, p=$ 0.032 ) and the cryotherapy alone (group $B, p<0.0001$ ), the plasma melatonin concentration significantly increased. The rise of plasma serotonin concentrations was higher in group B as compared to group $A$, but in both study groups the increase in plasma serotonin was statistically significant $(p<0.0001)$..

Conclusions:

Key words:

60 patients underwent a series of WBCT combined with kinesiotherapy (group A). 60 patients underwent a series of kinesiotherapy alone (group B). Before and after the therapy patients were examined by Rolland Morris Disability Questionnaire (RMDQ), and blood samples were collected for laboratory assessment.

WBCT combined with therapeutic exercises as well as kinesiotherapy used alone resulted in an increase in melatonin and serotonin plasma levels and an improvement in functional efficiency in patients with lumbar spine $O A$.

Osteoarthrosis (OA) is the most common disease affecting mankind. There are many physiotherapeutic methods of treating OA symptoms. One of them is whole body cryotherapy (WBCT). The aim of this study was to present the impact of WBCT combined with kinesiotherapy on functional efficiency and changes in plasma concentrations of serotonin and melatonin in patients with lumbar spine OA.

\section{article details}

Article statistics:

Full-text PDF:

Copyright Indexation:

Funding:

Conflict of interests: Corresponding author:

Open Access License:

Word count: 1,927; Tables: 0; Figures: 2; References: 26

Received: September 2020; Accepted: March 2021; Published: March 2021

http://www.balticsportscience.com

(c) Gdansk University of Physical Education and Sport, Poland

Celdes, Clarivate Analytics Emerging Sources Citation Index (ESCI), CNKI Scholar (China National Knowledge Infrastructure), CNPIEC, DOAJ, EBSCO - Central \& Eastern European Academic Source, EBSCO - SPORTDiscus, EBSCO Discovery Service, Google Scholar, Index Copernicus, J-Gate, Naviga (Softweco, Primo Central (ExLibris), ProQuest - Family Health, ProQuest - Health \& Medical Complete, ProQuest - Illustrata: Health Sciences, ProQuest Nursing \& Allied Health Source, Summon (Serials Solutions/ProQuest, TDOne (TDNet), Ulrich's Periodicals Directory/ ulrichsweb, WorldCat (OCLC)

This research received no specific grant from any funding agency in the public, commercial, or not-for-profit sectors. Authors have declared that no competing interest exists.

Marta Barłowska-Trybulec; Michałowskiego 12 Str., 31-126 Kraków, Poland; e-mail: marta.barlowska@uj.edu.pl; phone no. Tel. 126343397 int. 33

This is an open access article distributed under the terms of the Creative Commons Attribution-Non-Commercial-NoDerivatives 4.0 International (https://creativecommons.org/licenses/by-nc-nd/4.0/), which permits use, distribution and reproduction in any medium, provided the original work is properly cited, the use is non-commercial and is otherwise in compliance with the license. 


\section{INTRODUCTION}

Osteoarthritis (OA) is considered the most common disease affecting mankind. Experts estimate that $70 \%$ of the population older than 30 years suffer from low back pain (LBP), whereas the incidence of LBP among people aged 40 years and with age, the incidence of LBP increases in both in the female and male population [1, 2]. Whole body cryotherapy (WBCT) is physical treatment that has a positive effect on functional efficiency and affects the endocrine function of organism $[3,4]$. Exposure to extremely low temperatures in a cryotherapeutic chamber appears as a strong stress; however, the biological significance of melatonin and serotonin under the conditions of stress associated with exposure to low temperatures has not yet been fully understood [5-8].

Serotonin $(5-\mathrm{HT})$ is a tissue hormone and a neurotransmitter in the central nervous system. It is mainly produced in the pineal gland, as well as in the digestive system and blood cells. It is a direct precursor to melatonin and is formed from the amino acid L-tryptophan. L-tryptophan is transformed by the hydroxylase into 5-hydroxytryptophan, which is converted into serotonin to 5-hydroxytryptophan decarboxylase $[9,10]$. Serotonin regulates thermogenesis, blood pressure and food intake, which is important in the prevention and treatment of chronic diseases, including osteoarthrosis (OA). Previous studies indicate that 5-HT modulates the sexual behavior and significantly affects mood and well-being. This neurotransmitter plays an important role in the pathogenesis and treatment of anxiety-depressive and mental disorders related to stress. Its low level is often manifested by depression, anxiety or suicidal tendencies and aggression [11]. Melatonin (N-acetyl-5-methoxytryptamin) is synthetized at night by pineal cells. Melatonin is formed from the precursor of L-tryptophan in a process in which two enzymes play a key role: serotonin N-acetyltransferase (AA-NAT) and hydroxyindole-O-methyltransferase (HIOMT). The activity of these enzymes is subject to daily fluctuations, and the synthesis and release of melatonin is closely dependent on light exposure [12]. The effect of melatonin on the immune system and its antioxidant and regulatory activity in the organism is interesting in relation to the etiology and therapeutic treatment in chronic inflammatory and autoimmune diseases as well as in osteoarthrosis. The relationship between the circadian melatonin release and the rhythmic occurrence of disease symptoms in rheumatologic patients seems particularly important $[13,14]$.

The aim of the study was to assess the impact of WBCT combined with kinesiotherapy on functional efficiency and changes in plasma concentrations of serotonin and melatonin in patients with OA of the lumbar spine.

\section{MATERIAL AND METHODS}

The study group consisted of 120 patients (mean age $59 \pm 8$ years) with lumbar spine OA. These patients were randomly divided into two groups (group A and B) of 60 patients. Patients from group A were subjected to series of WBCT combined with therapeutic exercises, while patients from group B underwent therapeutic exercises alone.

Patients in group A received a series of 10 WBCT sessions over a two-week period excluding the weekend. Each session in a cryochamber lasted 3 minutes (temperature $-120 \stackrel{\circ}{ } \mathrm{C})$. Before each entrance to the cryochamber, patients had a blood pressure test. After leaving the cryochamber, the patients performed therapeutic exercises, the same as patients from group B. Patients from group B underwent therapeutic exercises similarly to patients from group A during 10 days excluding the weekend. A single training session lasted 30 minutes. The training consisted of stretching exercises of lower and upper limbs muscles, strengthening exercises of the back, abdomen and buttocks muscles with a Thera band tape, isometric exercises for the lower limbs, balance exercises on a Swiss 
ball and breathing exercises. Each exercise was repeated 8 times in three series, except for breathing exercises which were repeated 3 times.

Before and after the therapy, each patient was assessed with the Rolland Morris Disability Questionnaire (RMDQ). After collecting blood samples from each patient, plasma melatonin and serotonin levels were determined using commercial ELISA assay kits (ELISA Kit for Melatonin, CEA908Ge, Houston, USA; Serotonin ELISA Fast Track, BA E-8900, Germany) by ELISA (Enzyme-linked Immunosorbent Assay). Spearman's rank correlation and the Wilcoxon test were used to study the relationship between variables. A positive opinion of the Bioethics Committee of the Jagiellonian University was obtained (Opinion No. KBET/147/B/2014 of 26 June 2014 with an extension until 26.06.2020).

\section{RESULTS}

The results of statistical analysis showed that in patients from group A and in those from group B the mean values of RMDQ were reduced after the applied physiotherapeutic treatment. The improvement in functional efficiency using this questionnaire was 33\% in both study groups $(\mathrm{p}<0.0001)$.

After a series of WBCT combined with therapeutic exercises, as well as after a series of therapeutic exercises alone, an increase in melatonin plasma concentrations was observed. The average value of plasma melatonin concentration before WBCT was 36.72 $\pm 22.31 \mathrm{pg} / \mathrm{mL}$, while after a series of these treatments, the average concentration of this indolamine increased to $45.16 \pm 32.99 \mathrm{pg} / \mathrm{mL}$. In group B the mean value of plasma melatonin concentration before the series of therapeutic exercises reached $35.08 \pm 20.58$ $\mathrm{pg} / \mathrm{mL}$, while after kinesiotherapy this value increased significantly to $63.20 \pm 46.87 \mathrm{pg} /$ $\mathrm{mL}$ (Fig. 1).

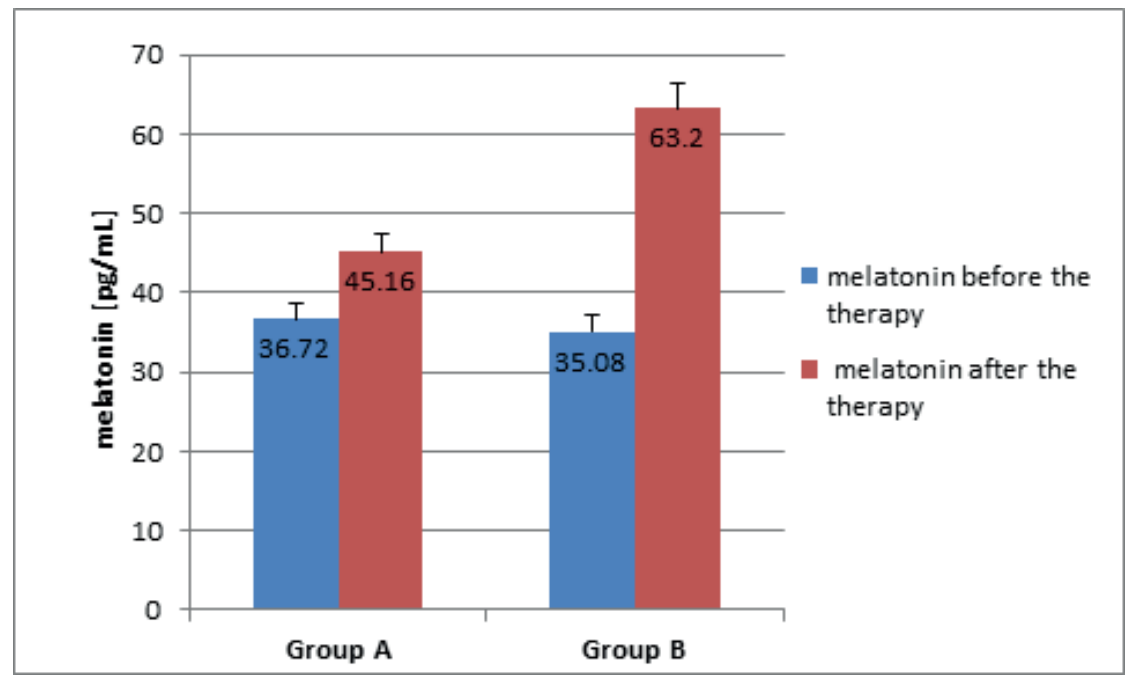

Fig. 1. Mean values of plasma melatonin concentrations before and after a series of WBCT combined with kinesiotherapy (group A) and a series of kinesiotherapy (group B); * $p<0.05$

These increases in melatonin plasma concentrations measured after the end of therapy were in both groups of patients statistically significant ( $p$ value for group A was $p=0.032$, and for group B it was $\mathrm{p}<0.0001)$, but the increase of plasma melatonin concentration was more pronounced in the group B $(28.12 \mathrm{pg} / \mathrm{mL})$ than in the group treated with WBCT combined with therapeutic exercises (8.44 pg/mL) (Fig. 1). 
After a series of WBCT treatments and after a series of therapeutic exercises, an increase in plasma serotonin concentrations in patients from both groups was observed. In patients from group A the basal serotonin plasma concentration (before WBCT combined with therapeutic exercises) was $49.39 \pm 19.71 \mathrm{ng} / \mathrm{mL}$, while after a series of treatments it increased to $63.83 \pm 31.04 \mathrm{ng} / \mathrm{mL}$ (Fig. 2).

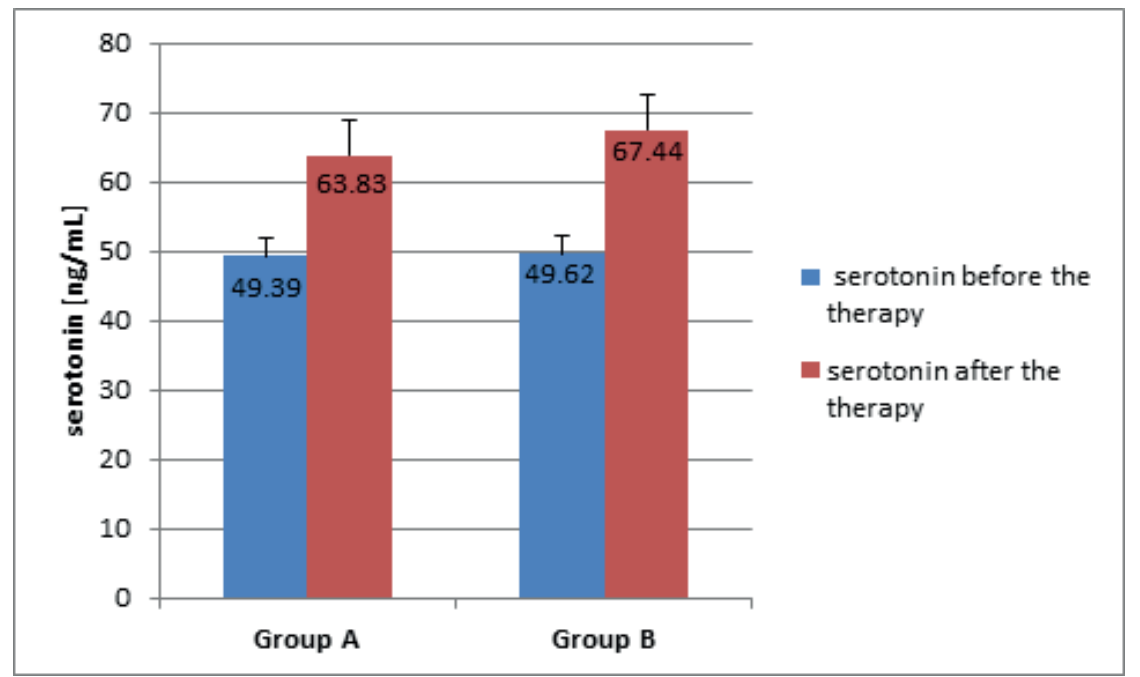

Fig. 2. Mean values of plasma serotonin concentrations before and after a series of WBCT combined with kinesiotherapy (group A) and a series of kinesiotherapy (group B); * $p<0.05$

In group B the average serotonin plasma concentration before kinesiotherapy averaged $49.62 \pm 24.13 \mathrm{ng} / \mathrm{mL}$. Following a series of therapeutic exercises it increased to $67.44 \pm$ $19.15 \mathrm{ng} / \mathrm{mL}$. The increase in serotonin concentrations after the therapy was higher in the B group (17.82 $\mathrm{ng} / \mathrm{mL})$ as compared to the changes of this amine in the plasma of patients from group A (14.44 ng/mL), but in both study groups the increase of plasma serotonin concentration was statistically significant ( $p<0.0001)$ (Fig. 2).

\section{DISCUSSION}

In present study, it was observed that after a series of WBCT, the low back pain was reduced, which was accompanied by an improvement (by 33\%) in functional efficiency assessed by RMDQ. Low back pain associated with everyday activities was decreased after the WBCT. This improvement was observed both in the group of patients undergoing WBCT combined with therapeutic exercises, as well as in patients with therapeutic exercises alone. There were no statistically significant differences between these groups of patients regarding the effects of physical procedures. Based on these observations it can be assumed that both WBCT and the therapeutic exercises themselves had a positive effect on the functional efficiency level of patients with OA of the lumbar spine. The beneficial effect of WBCT in relieving low back pain in patients with this disease is also documented by the results of another publication based on studies using the RMDQ [15]. It is worth mentioning that subjective pain feeling and morning stiffness occurring in patients with rheumatic diseases (rheumatic arthritis) correlates with the circadian rhythm of melatonin secretion [16].

The results of the current study indicate that therapeutic exercise has a stronger impact on the release of melatonin in patients with OA of the lumbar spine than WBCT combined with kinesiotherapy. No previous publications on such a relationship between melatonin concentration and LBP intensity were found; however, the results of German researchers 
indicate that the increase in serotonin secretion correlated with a significant reduction in pain in patients with low back pain undergoing WBCT [17]. This phenomenon could be associated with the release of serotonin in the brain and activation of the analgesic system in the brain stem by this neurotransmitter [18].

The difference in plasma melatonin concentrations in group B was $28.12 \mathrm{pg} / \mathrm{mL}$, while in group A it was smaller and amounted to only $8.44 \mathrm{pg} / \mathrm{mL}$. A similar tendency was also observed in the case of differences in serotonin concentrations between the two study groups. A slightly larger difference in serotonin concentrations could be seen in the group of patients undergoing only kinesiotherapy $(17.82 \mathrm{ng} / \mathrm{mL})$ compared to the group of patients undergoing a combination of WBCT and kinesiotherapy $(14.44 \mathrm{ng} / \mathrm{mL})$.

The results of the present study also suggest that differences in plasma serotonin concentration were lower in relation to the changes of plasma melatonin in both groups subjected to WBCT combined with exercises as well as those treated with kinesiotherapy alone. WBCT combined with kinesiotherapy as well as kinesiotherapy used separately correlated with increases in melatonin and serotonin plasma concentrations in patients with OA of the lumbar spine. These increases were more clearly marked among patients undergoing kinesiotherapy in comparison to the group subjected to WBCT combined with therapeutic exercises. It can be assumed that exposure to low temperatures caused the release of melatonin and serotonin in the group of patients subjected to a series of these physical procedures. According to other authors, an increase in melatonin concentrations in the blood correlated with an increase in the total antioxidant potential (TAS) as well as an improvement in the functional efficiency observed in the subjects. This observation confirms the important role of melatonin as a potent antioxidant in elderly patients and indicates that physical exercise may stimulate the production of this indolamine [19-21]. Therapeutic exercises, however, influenced the production of both these hormones and augmented their level in the blood. The results of other studies related to the effect of therapeutic exercises on plasma concentrations of melatonin and serotonin are controversial [22-24]. A significant improvement in the quality of sleep accompanied by a significant increase in plasma melatonin after a ten-week training session was shown. These results indicated that moderate or intense physical exercise, performed regularly over a longer period of time, significantly increases melatonin release, augments the antioxidant capacity of the organism and strengthens tissue protection. Therefore, physical activity could be recommended for people with sleep disorders [22].

The beneficial effect of melatonin on the synchronization of circadian rhythms and the increase in sleep efficiency in athletes is also confirmed by results of another study [23]. On the other hand, studies in which an attempt was made to assess the effect of physical activity on the urinary metabolite level of melatonin (6-sulfatoximelatonin) after twelve months of regular training in sedentary persons did not confirm this dependence [24]. Discrepancies in these results may be related to the lack of standardized methods of research and they may result from methodological differences.

There is also an inverse relationship between the production of melatonin and serotonin and the age of patients. The production of melatonin and serotonin is the highest in childhood and adolescence and decreases with age. In elderly people, the secretion of these amines is very low $[25,9]$. That is why, the initial level of these hormones was lower than average in the surveyed patients who represented the older population [26]. The results of the present study also allow finding a relationship between increases in hormone concentrations and an improvement in the functional efficiency and a reduction of low back pain associated with OA. 


\section{CONCLUSION}

WBCT combined with therapeutic exercises as well as kinesiotherapy used alone resulted in a significant increase in melatonin and serotonin plasma levels and functional improvement in patients with lumbar spine osteoarthrosis.

\section{ACKNOWLEDGEMENTS}

We would like to thank Elżbieta Broniatowska for statistical data analysis.

\section{REFERENCES}

[1] Goode AP, Carey TS, Jordan JM. Low back pain and lumbar spine osteoarthritis: how are they related? Curr Rheumatol Rep. 2013;15(2):305. doi: 10.1007/s11926-012-0305-z.

[2] Wenham CY, Conagham PG. New horizons in osteoarthritis. Age Ageing. 2013;42(3):272-278. doi: 10.1093/ageing/ aft043

[3] O’Dwyer T, O’Shea F, Wilson F. Exercise therapy for spondyloarthritis: a systematic review. Rheumatol Int. 2014; 34(7):887-902. doi: 10.1007/s00296-014-2965-7.

[4] Garczyński W, Lubkowska A. Physiotherapy in osteoarthritis of the lumbar spine. J Health Sci. 2013; 3(4): 118-130.

[5] Giemza C, Matczak-Giemza M, Ostrowska-Bieć E, Dolińska M. Effect of cryotherapy on the lumbar spine in elderly men with back pain. Aging Male. 2014;17(3):183-188. doi: 10.3109/13685538.2013.863860.

[6] Das SK, Farooqi A. Osteoarthritis. Best Pract Res Clin Rheumatol. 2008;22(4):657-675. doi: 10.1016/j.berh.2008.07.002.

[7] Jaworek J, Konturek SJ. Hormonal protection in acute pancreatitis by ghrelin, leptin and melatonin. World J Gastroenterol. 2014;20(45):16902-16912. doi: 10.3748/wjg.v20.i45.16902.

[8] Zhang HM, Zhang Y. Melatonin: A well-documented antioxidant with conditional pro-oxidant actions. J Pineal Res. 2014; 57: 131-146. doi: 10.1111/jpi.12162.

[9] Jaworek J, Leja-Szpak A, Nawrot-Porąbka K, et al. Effects of melatonin and its analogues on pancreatic inflammation, enzyme secretion, and tumorigenesis. Int. J. Mol. Sci. 2017;18(5):1014. doi: 10.3390/ijms18051014.

[10] Arreola R, Becerril-Villanueva E, Cruz-Fuentes C, et al. Immunomodulatory effects mediated by serotonin. J Immunol Res. 2015;2015:354957. doi: 10.1155/2015/354957.

[11] Garcia-Garcia AL, Newman-Tancredi A, Leonardo ED. 5-HT (1A) receptors in mood and anxiety: Recent insights into autoreceptor versus heteroreceptor function. Psychopharmacology (Berl.) 2014;231(4):623-636. doi: 10.1007/ s00213-013-3389-x.

[12] Tander B, Gunes S, Boke O, Alayli G, Kara N, Bagci H, Canturk F. Polymorphisms of the serotonin-2A receptor and catechol-O-methyltransferase genes: a study on fibromialgia susceptibility. Rheumatol Int. 2008;28(7):685-691. doi: 10.1007/s00296-008-0525-8.

[13] Rymaszewska J, Ramsey D, Chładzińska-Klejna S. Whole-body cryotherapy as adjunct treatment of depressive and anxiety disorders. Arch Immunol Ther Exp. 2008;56(1):63-68. doi: 0.1007/s00005-008-0006-5.

[14] Srinivasan V, Spence DW, Trakht I, Pandi-Perumal SR, Cardinali DP, Maestroni GJ. Immunomodulation by melatonin: Its significance for seasonally occurring diseases. Neuroimmunomodul. 2008;15(2):93-101. doi: 10.1159/000148191.

[15] Barłowska-Trybulec M, Zdunek K, Szklarczyk J, Jaworek J. Wpływ krioterapii ogólnoustrojowej na stan funkcjonalny odcinka lędźwiowego kręgosłupa u pacjentów z chorobą zwyrodnieniową. Medycyna Manualna. 2016;20(3,4):9-18.

[16] Cutolo M, Straub RH, Buttgereit F. Circadian rhythms of nocturnal hormones in rheumatoid arthritis: Translation from bench to bedside. Ann Rheum Dis. 2008;7(67):905-908. doi: 10.1136/ard.2008.088955.

[17] Schröder D, Anderson M. Kryo- und Thermotherapie: Grundlagen und praktische Anwendung. Stuttgart: G. Fischer Verlag, 1995; 7-20.

[18] Garcia-Garcia AL, Newman-Tancredi A, Leonardo ED. 5-HT (1A) receptors in mood and anxiety: recent insights into autoreceptor versus heteroreceptor function. Psychopharmacology (Berl.) 2014; 231(4): 623-636. doi: 10.1007/ s00213-013-3389-x.

[19] Robey E, Dawson B, Halson S, Gregson W, King S, Goodman C, Eastwood P. Effect of evening postexercise cold water immersion on subsequent sleep. Med Sci Sports Exerc. 2013; 45(7): 1394-1402. doi: 10.1249/MSS.0b013e318287f321.

[20] Robey E, Dawson B, Halson S, Goodman C, Gregson W, Eastwood P. Post-exercise cold water immersion: effect on core temperature and melatonin responses. Eur J Appl Physiol. 2013;113(2):305-311. doi: 10.1007/s00421-012-2436-3.

[21] Pilaczyńska-Szcześniak L, Karolkiewicz J, Strzelczyk A, et al. Melatonin concentrations and other parameters of blood antioxidant defense system in elderly men with various levels of physical activity. Pol Arch Med Wewn. 2004;111(5):557-562

[22] Cai ZY, Wen-Chyuan Chen K, Wen HJ. Effects of a group-based step aerobics training on sleep quality and melatonin levels in sleep-impaired postmenopausal women. J Strength Cond Res. 2014;28(9):2597-2603. doi: 10.1519/ JSC.0000000000000428.

[23] Leonardo-Mendonca RC, Martinez-Nicolas A, de Teresa Galvan C, et al. The benefits of four weeks of melatonin treatment on circadian patterns in resistance-trained athletes. Chronobiol Int. 2015;32(8):1125-1134. doi: 10.3109/07420528.2015.1069830.

[24] Thrift AP, Xiao L, Patel SR, Tworoger SS, McTiernan A, Duggan C. Effects of physical activity on melatonin levels in previously sedentary men and women. Cancer Epidemiol Biomarkers Prev. 2014;23(8):1696-1699. doi: 10.1158/10559965.EPI-14-0299. 
Baltic Journal of Health and Physical Activity 2021; 13 (1): 55-61

Journal of Gdansk University of Physical Education and Sport

e-ISSN 2080-9999

[25] Tander B, Gunes S, Boke O, Alayli G, Kara N, Bagci H, Canturk F. Polymorphisms of the serotonin-2A receptor and catechol-O-methyltransferase genes: a study on fibromialgia susceptibility. Rheumatol Int. 2008;28(7):685-691. doi: 10.1007/s00296-008-0525-8.

[26] Hardeland R. Melatonin and the theories of aging: a critical appraisal of melatonin's role in antiaging mechanisms. J Pineal Res. 2013;55(4):325-356. doi: 10.1111/jpi.12090. 